University of Wollongong

Research Online

SMART Infrastructure Facility - Papers

Faculty of Engineering and Information

Sciences

2018

Review of modelling air pollution from traffic at street-level - The state of the science

Hugh I. Forehead

University of Wollongong, hughf@uow.edu.au

Nam N. Huynh

University of Wollongong, nhuynh@uow.edu.au

Follow this and additional works at: https://ro.uow.edu.au/smartpapers

Part of the Engineering Commons, and the Physical Sciences and Mathematics Commons

Research Online is the open access institutional repository for the University of Wollongong. For further information contact the UOW Library: research-pubs@uow.edu.au 


\title{
Review of modelling air pollution from traffic at street-level - The state of the science
}

\begin{abstract}
Traffic emissions are a complex and variable cocktail of toxic chemicals. They are the major source of atmospheric pollution in the parts of cities where people live, commute and work. Reducing exposure requires information about the distribution and nature of emissions. Spatially and temporally detailed data are required, because both the rate of production and the composition of emissions vary significantly with time of day and with local changes in wind, traffic composition and flow. Increasing computer processing power means that models can accept highly detailed inputs of fleet, fuels and road networks. The state of the science models can simulate the behaviour and emissions of all the individual vehicles on a road network, with resolution of a second and tens of metres. The chemistry of the simulated emissions is also highly resolved, due to consideration of multiple engine processes, fuel evaporation and tyre wear. Good results can be achieved with both commercially available and open source models. The extent of a simulation is usually limited by processing capacity; the accuracy by the quality of traffic data. Recent studies have generated real time, detailed emissions data by using inputs from novel traffic sensing technologies and data from intelligent traffic systems (ITS). Increasingly, detailed pollution data is being combined with spatially resolved demographic or epidemiological data for targeted risk analyses.

\section{Disciplines \\ Engineering | Physical Sciences and Mathematics}

\section{Publication Details}

Forehead, H. \& Huynh, N. (2018). Review of modelling air pollution from traffic at street-level - The state of the science. Environmental Pollution, 241 775-786.
\end{abstract}




\section{Review of modelling air pollution from traffic at street-level - the 2 state of the science}

$3 \quad$ H. Forehead ${ }^{1}$, N. Huynh

4 SMART Infrastructure Facility, University of Wollongong, Wollongong, NSW, Australia

$5 \quad{ }^{1}$ corresponding author: hughf@uow.edu.au

7 Abstract

8 Traffic emissions are a complex and variable cocktail of toxic chemicals. They are the major

9 source of atmospheric pollution in the parts of cities where people live, commute and work.

10 Reducing exposure requires information about the distribution and nature of emissions. Spatially and temporally detailed data are required, because both the rate of production and the composition of emissions vary significantly with time of day and with local changes in wind, traffic composition and flow. Increasing computer processing power means that models can accept highly detailed inputs of fleet, fuels and road networks. The state of the science models can simulate the behaviour and emissions of all the individual vehicles on a road network, with resolution of a second and tens of metres. The chemistry of the simulated emissions is also highly resolved, due to consideration of multiple engine processes, fuel evaporation and tyre wear. Good results can be achieved with both commercially available and open source models. The extent of a simulation is usually limited by processing capacity; the accuracy by the quality of traffic data. Recent studies have generated real time, detailed emissions data by using inputs from novel traffic sensing technologies and data from intelligent traffic systems (ITS). Increasingly, detailed pollution data is being combined with spatially resolved demographic or epidemiological data for targeted risk analyses.

Capsule for submission: 
26 Technology and software now exist that permit the simulation of traffic emissions at sufficient

27 resolution to estimate the exposure of pedestrians, commuters and vulnerable populations

28 Keywords:

microsimulation; health; exposure; ITS; agent-based model; open-source

\section{$31 \quad 1$ Introduction}

This review was prompted by the need to better understand people's exposure to traffic

pollution on city streets. Broad-scale, background levels of pollution are usually well monitored in major cities, but it remains difficult to determine air quality data at street level in most places. Concentrations can be highly variable over short distances and intervals of time, due to fleet composition, congestion, weather (mainly wind) and the shape of street canyons. For examples of what can be achieved with sufficient resources, readers are referred to the programmes:

"Dispersion of Air Pollution and its Penetration into the Local Environment" in Westminster, United Kingdom (DAPPLE 2009), the "New York City Community Air Survey" in New York, USA (NYCCAS 2018) and vehicle-based measurements in Oakland, USA (Apte, Messier et al. 2017). Low cost wireless sensors show promise for the future, but currently there are only very few pollutants that can be measured well without expensive equipment. State of the science traffic emissions modelling provides estimates of a comprehensive suite of pollutants with fine spatial and temporal resolution, saving the considerable expense of monitoring equipment (Gois, Maciel et al. 2007). The data is localised to tens of metres at street level, enabling more accurate estimates of air quality for pedestrians, commuters, children and the aged. Once problems are identified, they can be mitigated with barriers, spatial buffers, improved ventilation in buildings, or alterations to the fleet (Batterman, Ganguly et al. 2015). 
49 The review starts by describing the effects of traffic emissions on air quality and why they are

50 difficult to quantify. Then we examine the risks to health and costs incurred by the suite of gases and aerosols that are produced on urban streets. The majority of the review focusses on the state of the science of modelling traffic emissions. We briefly describe some approaches that can give reasonable estimates of roadside air quality given limited data and resources. There are detailed reviews of each of the 4 main steps of microscopic traffic emissions modelling: trip generation, traffic simulation, emissions modelling and dispersion modelling. The first part contains a summary of the emerging new directions that combine simulation with sensors for real-time emissions mapping. The section ends with a summary table of case studies and recommendations for users.

\section{Understanding pedestrian exposure to traffic-related air}

\section{pollutants}

\subsection{Traffic pollution in cities}

Airborne pollution from traffic is a significant health hazard worldwide for the people who live in cities (UN-Habitat 2013). The amount of freight moved by light commercial vehicles has increased by $300 \%$ in recent decades, due to increases in the size of the service sector (Houghton, McRobert et al. 2003). Motor vehicles are responsible for a considerable fraction of many airborne pollutants (Table 1). As the numbers of vehicles using urban roads has increased, so has traffic congestion, exacerbating pollution, greenhouse gas emissions, delays and financial losses from wasted fuel and lost work time (Schrank, Eisele et al. 2015). The financial consequences can be considerable, even neglecting lost productivity. Each emitted tonne of particulate matter smaller than 2.5 microns $\left(\mathrm{PM}_{2.5}\right)$ cost US $\$ 208,000$ in Sydney, Australia and US\$141,000 in Melbourne (Aust, Watkiss et al. 2013). Policy makers require good data to understand the problem and to plan for the future. 
75 Table 1. Total annual Australian National Pollutant Inventory (NPI) emissions (kg/yr) for

76 industry and motor vehicles (National Motor Vehicle Emissions Inventory, NMVEI) in 2010

$77 \quad$ (Smit 2014)

\begin{tabular}{|c|c|c|c|}
\hline Pollutant & $\begin{array}{l}\text { NPI } \\
\text { industry }\end{array}$ & NMVEI & $\begin{array}{l}\text { MV } \\
\text { Contribution }\end{array}$ \\
\hline Acetaldehyde & $4 \quad 411,765$ & 8886,969 & $68.29 \%$ \\
\hline Acetone & 691,837 & 301,465 & $30.35 \%$ \\
\hline Acrolein & 11 & 314,000 & $100.00 \%$ \\
\hline Ammonia & $120,860,415$ & $6,313,888$ & $4.96 \%$ \\
\hline Benzene & $1,197,423$ & $4,099,173$ & $77.39 \%$ \\
\hline 1,3-Butadiene & 14,635 & 971,856 & $98.52 \%$ \\
\hline Cadmium & 32,053 & 237 & $0.73 \%$ \\
\hline Carbon monoxide & $1,388,700,000$ & $936,869,323$ & $40.29 \%$ \\
\hline Chromium & 590,406 & 502 & $0.08 \%$ \\
\hline Copper & 677,884 & 794 & $0.12 \%$ \\
\hline Cyclohexane & 473,055 & 664,516 & $58.42 \%$ \\
\hline Dioxins/Furans (i-TEQ) & 0.194 & 0.005 & $2.75 \%$ \\
\hline Ethylbenzene & 138,330 & $3,116,430$ & $95.75 \%$ \\
\hline Formaldehyde & $2,922,758$ & $2,005,013$ & $40.69 \%$ \\
\hline Lead & 687,463 & 17,171 & $2.44 \%$ \\
\hline Methylethylketone (MEK) & 700,618 & 77,818 & $10.00 \%$ \\
\hline n-Hexane & $1,709,621$ & $1,322,489$ & $43.62 \%$ \\
\hline Nickel & 772,525 & 267 & $0.03 \%$ \\
\hline Oxides of Nitrogen & $1,396,900,000$ & $305,601,721$ & $17.95 \%$ \\
\hline PAHs (BaP-equivalents) & 23,709 & 627 & $2.58 \%$ \\
\hline Particulate Matter $\leq 10.0 \mu \mathrm{m}$ & $1,238,329,933$ & $14,461,823$ & $1.15 \%$ \\
\hline Particulate Matter $\leq 2.5 \mu \mathrm{m}$ & $56,532,376$ & $11,684,995$ & $17.13 \%$ \\
\hline Selenium & 6,348 & 4 & $0.06 \%$ \\
\hline Styrene & 393,246 & 470,431 & $54.47 \%$ \\
\hline Sulfur dioxide & $2,509,400,000$ & $1,310,884$ & $0.05 \%$ \\
\hline Toluene & $2,525,696$ & $8,243,841$ & $76.55 \%$ \\
\hline Total Volatile Organic Compounds & $157,006,103$ & $107,329,985$ & $40.60 \%$ \\
\hline Xylenes & $1,882,125$ & 8,085 & $0.43 \%$ \\
\hline Zinc & $1,597,971$ & 47,352 & $2.88 \%$ \\
\hline
\end{tabular}

79 The toxic chemicals that comprise traffic emissions are released as gases and primary particles.

80 The two most commonly used fuels generate different mixtures of pollutants in addition to $\mathrm{CO}_{2}$ :

81 petrol vehicles are mainly responsible for emissions of carbon monoxide (CO), volatile organic compounds (VOCs), ammonia $\left(\mathrm{NH}_{3}\right)$ and heavy metals. Diesel vehicles produce most of the 
particles of 2.5 microns and smaller $\left(\mathrm{PM}_{2.5}\right)$ and oxides of nitrogen $\left(\mathrm{NO}_{x}\right)$ (Smit 2014). Diesel particulate matter (DPM) is composed of a core of elemental carbon surrounded by organic compounds including polycyclic aromatic hydrocarbons (PAHs), nitro-PAHs, small amounts of sulphate, nitrate, metals and other trace elements. These particles have a large surface area, making them susceptible to adsorption to lung tissue (Wichmann 2007).

The chemistry of emissions is highly variable in time and space (BTRE 2005) and the composition affects toxicity (Rückerl, Schneider et al. 2011). The composition of the mixture of gases and particles changes with time after release from the exhaust pipe. There are a number of possible chemical reactions, coagulation and condensation of gases, aerosols and particles. The transformations can be affected by local conditions such as the concentration of pollutants, temperature, turbulence (particularly wind), sunlight and humidity. For example, the concentrations of particular species, such as $\mathrm{NO}_{x}$, can determine the production of secondary pollutants such as ozone (Ryu, Baik et al. 2013).

Although numbers of vehicles on roads continue to increase, emissions regulations have mandated increased efficiency of engine technologies to reduce outputs of harmful emissions. Older, carburetted cars released 10 times the $\mathrm{HC}, 4$ times the $\mathrm{CO}$ and 3 times the $\mathrm{NO}_{\mathrm{x}}$ of newer multi-point ignition engines (Qu, Li et al. 2015). However, while newer cars release less pollution, the expected reduction in emissions from modern vehicles will only be realised if their emissions control equipment is properly maintained (Marquez and Salim 2007).

\subsection{Health effects of traffic pollution}

Although traffic emissions (Table 1) are not the major fraction of airborne pollution in cities, they are a major source of airborne pollution for people, because traffic occupies space close to walkways, residences, workplaces and schools. The traffic intensity on the nearest road to a 
person's home address was linked to mortality in a long-term study (Beelen, Hoek et al. 2008).

Diesel exhaust poses the greatest risk of cancer of any air pollutant (Wichmann 2007). An extensive sampling program for volatile organic compounds (VOCs) in New York City found that proximity of roads and traffic signals explained $65 \%$ of variation in atmospheric concentrations of benzene (Kheirbek, Johnson et al. 2012). Commuters travelling by bicycle, bus, automobile, rail, walking and ferry are exposed to concentrations of ultrafine particles that can elicit acute effects in both healthy and health-compromised individuals (Knibbs, Cole-Hunter et al. 2011). For a typical urban commuting journey in Alameda County, USA, personal exposure to $\mathrm{NO}_{\mathrm{x}}$ was found to increase from $29 \mathrm{ppb}$ (parts per billion, $10^{-9}$ ) indoors to $96 \mathrm{ppb}$ outdoors ( $\mathrm{Su}$, Jerrett et al. 2015). In a study of different modes of travel to work, the greatest rates of exposure to ultrafine particles were found for those walking or cycling along highly trafficked routes and using buses (Spinazzè, Cattaneo et al. 2015). Some occupations are at significantly elevated risk from traffic emissions. Exposure of traffic policemen in Beijing to polycyclic aromatic hydrocarbons $(\mathrm{PAH})$ was nearly an order of magnitude greater than regulatory limits (Liu, Tao et al. 2007) (Hu, Bai et al. 2007, Liu, Tao et al. 2007). Bus drivers and mail carriers in Copenhagen, Denmark were found to have elevated concentrations of biomarkers for DNA damage (Hansen, Wallin et al. 2004).

Evidence of harm from traffic pollution is abundant and mounting, it affects multiple systems of the body. For example, there are links to a range of serious damages to the heart, some fatal. Emissions of $\mathrm{NO}_{2}$ can cause a $5 \%$ enlargement of the right ventricle and $3 \%$ increase in its volume after emptying (end diastolic volume). These changes are quantitatively similar to those caused by diabetes or smoking (Holguin and McCormack 2014). Traffic emissions have also been associated with increased levels of inflammatory nasal markers, increased urinary concentrations of urea and metabolites of nitric oxide (Steerenberg, Nierkens et al. 2001). Long term exposure to traffic and $\mathrm{PM}_{2.5}$ reduced respiratory function in adults (WHO 2013, Badyda, Dabrowiecki et al. 2015, Rice, Ljungman et al. 2015) and the irritant and carcinogenic chemicals 
cause a range of morbidities including asthma. Children's rapidly growing lungs and immature immune systems make them susceptible to diseases associated with airborne pollution from traffic, such as asthma, allergy, bronchitis and deficits of lung function and growth (Chen, Salam et al. 2015, Gehring, Beelen et al. 2015).

The capacity of particulate pollution to cause harm is related to its size, surface area and composition. Particulate matter (PM) is usually classified into size ranges: $\mathrm{PM}_{10}$ is less than or equal to $10 \mu \mathrm{m}$ (micrometres, $10^{-6} \mathrm{~m}$ ) in diameter, $\mathrm{PM}_{2.5}$ is less than or equal to $2.5 \mu \mathrm{m}$ and $\mathrm{PM}_{0.1}$, or ultrafine particles, are less than or equal to $100 \mathrm{~nm}$ (nanometres, $10^{-9} \mathrm{~m}$ ). The smaller the size of the particle, the deeper it can travel into the lungs. Ultrafine particles can reach the alveoli where $50 \%$ are retained in the lung parenchyma (Valavanidis, Fiotakis et al. 2008). Linear doseresponse associations have been found between particulate matter (PM) pollution and mortality in the United States (Daniels, Dominici et al. 2000), Canada (Requia, Higgins et al. 2018) and in Europe (Samoli, Analitis et al. 2005). Most of the urban $\mathrm{PM}_{2.5}$ emissions are due to traffic, particularly diesel-fuelled trucks and buses (Chan, Simpson et al. 1999, Salameh, Detournay et al. 2015). A review of adverse health effects of short-term exposure to $\mathrm{PM}_{2.5}$ in China showed a $0.40 \%$ increase in non-accident mortality with every $10 \mathrm{ng} \mathrm{m}^{-3}$ increase in concentration $(\mathrm{Lu}, \mathrm{Xu}$ et al. 2015). Recent work has connected urban exposure to $\mathrm{PM}_{2.5}$ with an increased risk of low birth weight (Coker, Ghosh et al. 2015). Commonly, reports of particulate pollution have $\mathrm{PM}_{2.5}$ as the smallest class, but this may not be adequate. Not only do ultrafine particles have the capacity to penetrate deep into the airways, but their greater surface area and porosity give an increased capacity to adsorb and retain toxic substances (Valavanidis, Fiotakis et al. 2008). Some authors suggest that it is important to extend consideration to particles of $1 \mathrm{~nm}$ size, due to the potential for coagulation and condensation processes at the street level. New particles can form through chemical transformation processes (secondary production) over time in locations like road tunnels, with prolonged residence times and increased concentrations. For example, the mass of secondary nitrate was four times that of primary nitrate in fine aerosols at a site in 
159 Brisbane, Australia (Chan, Simpson et al. 1999). Transformation processes include aggregation, 160 homogeneous nucleation and changes from gas to particle. Because of the complexity of the chemistry and of the modelling, it is particularly important to validate model results with in-situ sensor measurements (Kumar, Ketzel et al. 2011).

It is common practice to reduce PM pollution by diesel fuelled vehicles with the use of particle traps. These devices can be very effective if used and maintained properly, but an undesirable byproduct is a substantial increase in the production of primary $\mathrm{NO}_{2}$ (Feng, Ge et al. 2014, Tang, Zhang et al. 2014, $\mathrm{He}, \mathrm{Li}$ et al. 2015). The resulting effect of $\mathrm{NO}_{2}$ on premature mortality is greater than ten times that of $\mathrm{PM}_{2.5}$ in pre particle-trap concentrations (Harrison and Beddows 2017).

Modelling of transport in Adelaide, Australia showed the benefits in reduction of pollution and other health benefits of switching commuter travel from private vehicles to public transport. If $40 \%$ of vehicle kilometres travelled were changed to alternative transport by 2030 (projected population $1.4 \mathrm{M}), \mathrm{PM}_{2.5}$ would decline by about $0.4 \mu \mathrm{g} \mathrm{\textrm {m } ^ { - 3 }}$. This was estimated to reduce adverse health effects by 13 deaths/year, and 118 disability-adjusted life years. There were many more benefits predicted due to improved physical fitness through walking or cycling (Xia, Nitschke et al. 2015).

\section{Traffic emissions modelling: summary of the process $\&$ most}

\section{9 commonly used models}


181 Detailed information is required to identify the locations of greatest risk to pedestrians, the "hotspots" of concentrated pollution. The data is necessary for determining the effects of long-term exposure for those living or working near busy roads. Details of concentration and composition cannot be well represented by interpolating measurements from sparsely distributed sensors. Internet of Things (IoT) sensors that measure air quality are cheap and readily available, but these are yet to be proven in the roadside setting (Forehead, Murphy et al. 2017). The spatial and temporal resolution of traffic emissions models has been increasing over time with improvements in data collection, computational power, modelling and technology. Simulations with coarse resolution, that are simpler and quicker to use, are still commonly used for regional inventories of pollutants. However, microscopic simulations with detailed inputs are required to represent details of complex, congested traffic, (Austroads 2006). A survey of traffic emissions modelling by the US Department of Transportation identified microscopic simulations as the state of practice and that "aggregate network performance data created by traditional static assignment models is not suitable for estimating emissions accurately" (Balaji Yelchuru, Adams et al. 2011). Readers are also referred to 2 excellent earlier reviews of microscopic emissions modelling methods: (Fallah Shorshani, André et al. 2015, Fontes, Pereira et al. 2015). These models can show pollutant hot-spots and help estimate exposure for vulnerable populations, such as those in hospitals, child care, parks, aged care facilities (Batterman, Ganguly et al. 2015). Fine-scale resolution is needed to reduce uncertainty in applications such as health impact assessments (HIA), that are increasingly a part of project planning (BTRE 2005, National Research Council Committee on Health Impact 2011). Traffic emissions models can be used for other risk assessments, such as predicting increases or decreases in emissions due to infrastructure changes, roadworks or events. They can model the exposure of pedestrians to traffic pollution with different designs of intersections (Qiu and Li 2015) and the effectiveness of mitigation strategies that separate pedestrians and traffic (El-Fadel 2002). 
207

\subsection{Simpler approaches}

Where detailed data are not available, a simpler macroscopic approach may be appropriate.

Alternatives include the use of satellite aerosol optical depth data, in conjunction with a land use regression model, to add a temporal estimate to spatial data regarding the origins of $\mathrm{PM}_{2.5}$.

Validation of this approach in Florida, USA gave coefficient of determination of 0.63 , comparable with studies that use aerodynamic-meteorological models (Mao, Qiu et al. 2012). A land use regression model was used with a simple atmospheric dispersion model to estimate the daily average particle number on a freeway. Inputs were annual averaged wind speed and annual average daily traffic counts, errors averaged 6\% across 98 sites (Olvera, Jimenez et al. 2014).

Traffic sources of airborne pollutants can be separated from background sources using air quality measurements from a single station and meteorological data. A freely available semi-empirical (box model) pollution model and a spreadsheet-based traffic model (Vehicle emissions prediction model) were designed for Auckland, New Zealand. Results were verified in a study, using ambient records of 2 air pollution monitors. The best estimations were achieved for nitrogen oxides; $\mathrm{PM}_{10}$ was difficult to distinguish due to interference from marine aerosols (Elangasinghe, Dirks et al. 2014). In developing countries, measuring traffic flow via new technologies may be too expensive or difficult to implement. A macroscopic traffic flow model can be a good choice when little traffic data is available. The Lighthill and Whitham (1955) model represents traffic in differential equations, using theories of compressible fluids. Only 6 days of data were used for estimates of density and travel times on a busy arterial road in Chennai, India. Results had mean average percentage errors ranging from $12.7 \%$ to $45.7 \%$ when checked with observations (Kumar, Vanajakshi et al. 2011). Another approach that requires little data is a seasonal Autoregressive Integrated Moving Average (SARIMA) model. A 24 hour simulation of traffic flow on an arterial roadway used only 3 days of data and errors ranged from just 4\% to 10\% (Kumar and Vanajakshi 2015). The publicly available Industrial Source Complex 
232 Short Term model (ISCST3, US EPA), was used to attribute airborne $\mathrm{PM}_{10}$ pollution to different 233 sources, including transport in Kanpur City, India. GIS was used to break up the study area into

$2342 \mathrm{~km}$ x $2 \mathrm{~km}$ grids. Resolution could be adjusted to any time and space (Behera, Sharma et al. 235 2011).

$237 \quad 3.3$ Microscopic traffic emissions models

238 Microscopic traffic emissions modelling typically comprises a series of sub-models, each

239 generating the input data for the next (Fig. 1). First is trip and fleet generation, then the traffic 240 model, traffic emissions and finally, the dispersion of emissions may be modelled. The number 241 of steps used can vary according to the application. The fleet of vehicles can be built from 242 databases, commonly from vehicle registration. Trip information can be derived from traffic 243 sensors and demographic data, such as the census and journey to work surveys. A traffic model 244 takes the trip data and generates the fleet activity on the road network. That information is fed 245 into an emissions model together with vehicle emissions factors to generate the emissions data 246 for the network. In some cases a dispersion model is added to predict the dispersion of 247 emissions away from the vehicles and the roadway. 


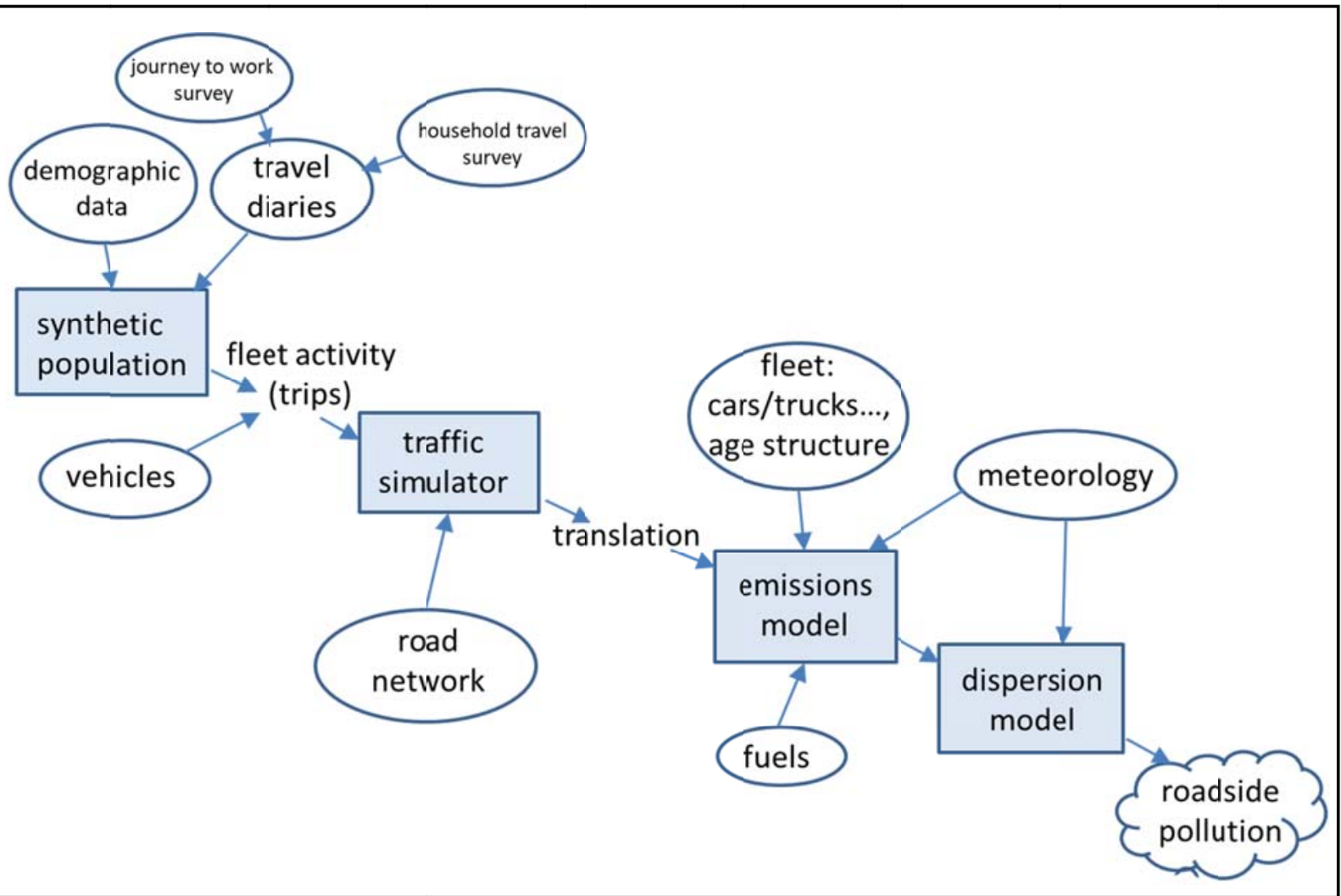

Figure 1. Modelling framework for estimating population exposure to traffic emissions. The 4 model steps are represented by the rectangles on the diagonal, the text in ovals shows the input data.

A synthetic population is often used as a foundation for a traffic simulation. It populates a study area, dwelling by dwelling, with people distributed into realistic households. The population is constructed from publicly available averaged demographic information, such as a census. For details of the process, see Huynh, Namazi-Rad et al. (2013). The people in households can then be assigned vehicles in a realistic manner.

Traffic simulations need realistic 'trips,' or journeys as inputs for vehicles; these are usually compiled into origin-destination (OD) matrices. Trips are defined by their origin, destination and purpose, such as journeys to work, to school or to shops. They can be built or calculated with data from a range of sources, including: surveys of journeys to work and of household travel, 
census data on population, employment and residences, freight movements, parking and transport networks including road rail, bus and ferries. There are a range of models that build trips from this data, including (in order of increasing complexity) sketch-planning models, strategic-planning models, trip-based models and activity-based models (Castiglione, Bradley et al. 2015). Generally, activity-based models are used to build trips for a day, with the expectation that no variation will occur. This is, of course, unrealistic, since unexpected changes occur, due to any number of unplanned events. Rescheduling in an activity-based model allows for unexpected changes, such as car accidents or time-table changes in public transport. The FEATHERS activity-based schedule generator simulates the behaviours of mutually independent individuals or actors. The state of a transport network can be influenced by actor behaviour and external phenomena. The actors interpret changes via perception filtering and adapt their schedules accordingly. This in turn affects the network as demand changes, giving a more realistic set of behaviours for microscopic traffic models. A limitation of the framework is that it can only change routes before they are started, once a journey has begun, it is fixed (Knapen, Bellemans et al. 2014). TRANSIMS (US EPA, Federal Highway Administration) is an opensource system of models that comprises a population synthesiser, an activity generator, routing, and a microscopic traffic simulation. The system offers much, but the data requirements are large and the calibration process can be challenging (Zhang and Cai 2016).

GPS sensors can substantially improve traffic monitoring. A one second sampling rate was found to be required to identify events such as vehicle stops, but aggregation to a 5 second resolution was sufficient for trip identification. Identification of stops in trips could be improved by combining map information with movement data to reduce false positives, such as pauses due to traffic congestion, or false negatives such as the missing of short stops (Shen and Stopher 2013). To give correct placement of a vehicle on a road segment in real time, GPS location was matched to speed and travel time data from cars, using an algorithm that incorporated a sequence of hidden-Markov models (Szwed and Pekala 2014). Commercial software is available 
to translate GPS data into trips. However, a study that compared two products using the same input data showed a discrepancy of $12 \%$ of trips between results. Errors included incorrectly splitting single trips or failing to identify some trips (Stopher, Greaves et al. 2013). A Bayesian approach was used to integrate data from Bluetooth, loop detectors and GPS for real-time traffic prediction. The method dramatically improved the accuracy of information from loop detectors on an arterial corridor in Brisbane, Australia (Nantes, Ngoduy et al. 2015).

Origin-destination (OD) data was generated from archived public transport data from smart cards, in conjunction with street maps and timetables in Žilina, the Slovak republic. It was possible to infer details such as in-vehicle travel and walking times for segments of a journey (Jánošíkova, Slavík et al. 2014). Calibration software (W-SPSA) used a weighting matrix to allow for correlations between inputs to OD matrixes (Antoniou, Lima Azevedo et al. 2015). Algorithms based upon evolutionary simulations were used to make choices regarding route choices depending on time and toll cost. The result can incorporate some amount of randomness.(Nagel, Kickhöfer et al. 2014).

Technology has increased the range of options available for monitoring traffic movements. Modern traffic data collection includes technologies that range from simple inductive loop sensors to piezo-electric, magneto-resistive studs, tirtle (laser) and piezo-WIM (weight in motion) sensors. The latter instruments can give details of vehicle class, by determining the mass and number of axles of a passing vehicle. Sensors are often integrated with a traffic control system, such as the Sydney Coordinated Adaptive Traffic System (SCATS), used in 26 countries. It has a software interface, SCATSIM, to link the traffic management system to microscopic traffic models. Some authorities monitor vehicle traffic by tracking signals from Bluetooth or WiFi devices and technologies such as GPS or automatic number plate recognition (ANPR) cameras. These activities are restricted to varying degrees by privacy legislation. 
313 ITS systems can provide cost savings, better coverage and increased accuracy over more labourintensive methods of data collection. The integration of large collections of detailed and timely trip and locational data offer the opportunity for accurate modelling of emissions that is highly temporally and spatially resolved. (Vasantha Kumar and Vanajakshi 2014).

Bluetooth and WiFi digital radio transmitters can be used to monitor vehicle movements.

Transmitters are found in many mobile electronic devices, including hands-free speaker systems for mobile phones, headsets and music players. Each device broadcasts its unique Media Access Control (MAC) address. Bluetooth transmitters have ranges from $3 \mathrm{~m}$ (class 3 devices) to $100 \mathrm{~m}$ (class 1 devices). The signal can be detected at the roadside and successive readings processed to give information relating to speed and route (Bachmann, Abdulhai et al. 2013). WiFi, signals can also be used and that system has a faster discovery time (about $1 \mathrm{sec}$ ) than Bluetooth (almost 10 sec) (Abedi, Bhaskar et al. 2013). There are a number of potential difficulties to be considered when using Bluetooth monitoring. There may be an uneven demographic distribution of Bluetooth devices in cars, a single device may be detected by multiple scans at busy locations and there are devices used outside motor vehicles by pedestrians, cyclists and on trains. The signals must be filtered to resolve these ambiguities (Abbott-Jard, Shah et al. 2013, Michau, Nantes et al. 2013). Early implementations of speed detection with Bluetooth were cited as problematic, with automated number-plate recognition being more reliable at higher speeds (Abbott-Jard, Shah et al. 2013). However, Bluetooth has become widely adopted for traffic monitoring and management (Aliari and Haghani 2012, Bachmann, Roorda et al. 2013, Juster, Young et al. 2014, Smith, Hainen et al. 2014). It has been used to verify the accuracy of a large dataset of probe vehicle data (Kaushik, Sharifi et al. 2014) and to give cheap \& cost-effective queue measurement (Alghamdi, Nadeem et al. 2014). The technology was used in Brisbane, Australia for modelling travel times, giving much better predictions than the historical average (Khoei, Bhaskar et al. 2013) and in Lincoln, USA, increasing the accuracy of predictions over aggregated link and corridor travel times (Wu and Rilett 2014). Only limited numbers of signals from wireless devices 
are needed to significantly increase the understanding of traffic flows. The South Australian Bluetooth system achieves a sample rate of about $15 \%$ of vehicles, better on arterial roads, mostly due to the presence of freight vehicles. The system is good enough that the Department of Planning, Transport and Infrastructure does not buy any external traffic data. It has been used for a number of purposes, including automated incident detection (AID) and to monitoring compliance with permits for traffic controls for roadworks. The department can see if traffic is being slowed down outside the times stipulated by a permit (Southern 2015). As far back as late 2015, a number of private companies were already advertising Bluetooth systems for monitoring traffic and other purposes.

Public concerns about privacy can potentially be an obstacle to the use of location technologies that scan private wireless devices. An EU project to develop collaborative transport emphasised the need to make efforts to gain the acceptance by travellers for the sharing of information required for many of the technologies (Penttinen, Diederichs et al. 2014). In an effort to avoid privacy concerns around the collection of data from privately owned wireless devices, real-time data from buses was used to estimate travel time for other vehicles on urban arterial routes (Vasantha Kumar and Vanajakshi 2014). Public concerns can also be addressed through education and the careful design of a system. The Bluetooth scanning system in South Australia automatically truncates scanned MAC addresses to make them anonymous and deletes them at the end of each day (Southern 2015). However, local legislation may actually preclude use of the technology in some locations. For example, Bluetooth signals cannot be used to sense private vehicles in Western Australia (Maddock 2015). A recent study (Chong-White, Millar et al. 2014) examined the environmental benefits of the Sydney Coordinated Adaptive Traffic System (SCATS) system using traffic data from e'Tags (in-vehicle electronic wireless devices for toll system) on a stretch of Military and Spit Roads in Sydney. It was found that the system was effective in reducing travel times, but that emissions reductions were not consistent across the 
network (Chong-White, Millar et al. 2013). The trial was abandoned due to privacy concerns with the e'Tag data.

ITS can improve the reliability of data from loop detectors. The addition of information from only a few probe vehicles equipped with GPS and Bluetooth scanning can significantly improve traffic speed estimates (Bachmann, Roorda et al. 2013). The fusion of multiple mobile data sources, including sensors, probe vehicles, Bluetooth and GPS, increases the accuracy of estimates of traffic speed. With only $5 \%$ probe vehicles, the root mean square error can be reduced by up to $80 \%$. There are a number of methods for combining data. A comparison tested five of these: distributed fusion, artificial neural networks, Kalman filters, fuzzy integrals and ordered weighting average. The methods were validated using a simulation model of a major freeway; the first three methods produced the best results (Bachmann, Abdulhai et al. 2013).

Private businesses are becoming the source of ever-increasing amounts of data. INRIX Inc. is based in the USA that provides real-time traffic information in over 40 countries. The company claimed that as of January 2015, they were collecting information about roadway speeds from “over 185 million real-time anonymous mobile phones, connected cars, trucks, delivery vans and other fleet vehicles equipped with GPS locator devices.” By May 2018, this number had increased to over 300 million (INRIX 2018).

\subsection{Traffic simulation models}

Traffic models represent vehicle movements on a road network with varying levels of detail.

There are many traffic models available, with updates and replacements constantly improving accuracy and versatility. A significant limitation to modelling efforts in many jurisdictions though, is the difficulty and expense in obtaining real traffic data for validation for more than a few major roads. 
supplier

model type

\begin{tabular}{lll} 
model name & supplier & model type \\
\hline \hline Aimsun & TTS Group, Singapore & car following \\
\hline MAS-T2er Lab & University of Porto, Portugal & agent-based \\
\hline MITSIMLab & MIT, USA & agent-based, open source \\
\hline PARAMICS & Pitney Bowes Software, UK & car following, lane changing \\
\hline SUMO & ITS, Germany & car following, open source \\
\hline TransModeler & Caliper Corp, USA & car following \\
\hline TSIS-CORSIM & McTrans Center, USA & agent-based \\
\hline VISSIM & PTV Group, Germany & car-following \\
\hline TRANSIMS & US EPA, USA & agent-based, open source \\
\hline
\end{tabular}

The level of detail used in traffic models depends upon the purpose of the modelling effort and the resources available. For example, in regional or national emissions inventories, results need to be comparable between jurisdictions, times and to be reproduced easily. These uses do not require resolution of seconds or tens of metres, so a strategy with a low to intermediate level of detail is generally used. Such macroscopic models may use analytical techniques such as fluid dynamics or simulations to model flows or platoons of traffic. Fine scale microscopic models (Table 2) deal with individual vehicles with second to second resolution or better. These are generally either cellular automaton models, where vehicles navigate according to rules with varying degrees of stochasticity, or car-following models, where vehicle to vehicle interactions are based upon differential equations. Mesoscopic simulations operate at an intermediate level of detail, lengths of road or groups of vehicles (Kokkinogenis, Sanchez Passos et al. 2011). Since the object of this review is the state of the science in modelling for cities, it focusses on microscopic modelling.

Table 2. Popular microscopic traffic simulation software 
In a traffic simulation, the smallest component of a road network is called a link. The number of links must be at least equal to the number of intersections. In addition, any changes in a road, such as a curve or gradient should be represented by a separate link. There is an upper limit to the resolution of a traffic simulation on a network, beyond which vehicle information can be missed. This is particularly the case for low traffic density. The length of a link must be sufficient that all vehicles can be detected over the duration of a model's time step. The risk of a vehicle being missed is proportional to the traffic's sparsity and speed; so the length of a link needs to be calibrated to traffic conditions and the simulation's temporal resolution (Fontes, Pereira et al. 2015). Long-run estimates of large areas can be challenging to calculate with such detailed models, because of the computational effort required (Fallah Shorshani, André et al. 2015).

Microscopic traffic simulations provide detailed representations of network behaviour by modelling time-varying demand patterns and the choices and behaviours of individual drivers. Simulations represent all vehicles individually, typically with a one second resolution. Algorithms based upon evolutionary simulations can make decisions regarding route choices depending on time and toll cost. Results can be improved by including some degree of randomness in the calculations. This approach allows the fleet to respond to congestion in a realistic manner (Nagel, Kickhöfer et al. 2014, Barthélemy and Carletti 2017). Models are calibrated for local driving behaviours such as car-following and lane changing. Capturing details of instantaneous speeds and acceleration rates increases the accuracy of emissions estimates, because the quality and quantity of vehicle emissions change with deviations from a steady speed (Austroads 2006, Chen and $\mathrm{Yu}$ 2007). As congestion increases, so does the incidence of speed changes and the emission of CO and HC (Smit 2006). Lane changing behaviour can significantly change traffic flow, many models simplify the manoeuvre as an instantaneous transition, but it generally takes from 1 to $16 \mathrm{~s}$. In addition, the lane-changing behaviours of trucks and cars on arterial roads have been found to be so distinct that they needed to be modelled differently (Cao, Young et al. 2013). 
428 Software is often used to improve the calibration process; for example W-SPSA, which includes a weighting matrix to allow for correlations between inputs, such as road sensor data (Antoniou, Lima Azevedo et al. 2015). Evolutionary algorithms can also be used for calibration. A study that used evolutionary algorithms for calibration of a county-wide simulation found that there was greater benefit to the accuracy of results by allocating effort to coding of the network and traffic demand, than to the calibration process (Smith, Sadek et al. 2008).However, other researchers found that dealing with easily identifiable errors in data markedly improved the results of a cityscaled microscopic traffic model. Errors from sensors were a significant problem when using automated methods for calibrating model parameters and making estimations for OD matrixes. (Jha, Gopalan et al. 2004).

There are a number of promising new approaches to traffic modelling in the literature. A Chinese study used a deep-learning-based predictive traffic model with large traffic datasets. A stacked autoencoder model learned generic traffic flow features; the method dealt with spatial and temporal correlations (Lv, Duan et al. 2015). Real-world mobile sensing data was used on an arterial road to estimate trajectories for the entire traffic population, as input to the CMEM emissions model. Adding random noise to the model's cruise mode improved estimation results 444 (Sun, Hao et al. 2015).

To assist in selecting from the large range of models on offer, a meta-modelling technique has been used to compare and select models and to optimise parameters. Intelligent surrogate modelling tested models in univariate and multivariate frameworks (Vlahogianni 2015). Examination of emissions modelling of Brisbane traffic showed that the majority of errors occurred not in the model specification, but the input data, particularly related to congested conditions. The models performed well under free-flowing conditions, but errors increased in the transitions to congested and very congested conditions (Zhu and Ferreira 2013). 


\subsection{Emissions models}

Emissions models operate at the same range of scales as traffic models and similarly, oversimplification leads to inaccurate results. The emissions from a vehicle are worst when the engine is started following an extended period of inactivity, so called "cold-starts." The severity of pollution increases with the duration of standing or "soak" time (Gao and Johnson 2009). Formation of secondary organic aerosols (SOA) decreased by a factor of 3 to 7 times between cold-start and hot-start tests in light-duty petrol passenger vehicles. To make things worse, after three hours of oxidation in the atmosphere, the concentrations of SOA from cold-start running could measure up to six times the concentrations found in the primary emissions (Gordon, Presto et al. 2014). A study of the effects of the aggregation of inputs to models found that cold start emissions contributed $67 \%$ to total road HC emissions. The next most important factors were the season and vehicle registry data, such as vehicle types and model years (Sider, GouletLanglois et al. 2015). Most emissions models include calculations that account for the age and structure of the fleet and meteorology.

Other sources of emissions from vehicles include brakes, particles released by the shear forces between vehicle tyres and the road and the evaporation of fuel from fuel tanks and lines at raised temperatures. These sources were often neglected in early emissions models, but are increasingly included in updated versions (European Environment Agency 2007). Evaporative emissions in Europe range from less than 3\% to around $16.5 \%$ of total non-methane volatile organic compounds (NMVOCs). These losses are mainly from petrol driven vehicles and have been decreasing in recent years with the use of control systems in newer models (Mellios and Ntziachristos 2012). Wet conditions should decrease tyre wear and new road surfaces increase wear (Mellios and Ntziachristos 2012). Not all of this material is airborne, so emission factors are required in models to calculate the contribution (European Environment Agency 2007). 
Emissions factors are parameters used to calculate emissions for particular chemicals and particles in vehicle exhausts. Databases for vehicle emission factors are usually specific to their country or region, for example HBEFA, is a European database of emissions factors for all current vehicle categories. It incorporates factors for different driving conditions, hot/cold running and evaporative emissions. The emission factors are generated by emissions models validated with measurements in laboratories and on roads. Originally developed by agencies in Germany, Switzerland and Austria, now funded by the EU (ERMES 2015, HBEFA 2015). HBEFA has also been found to be suitable for the Chinese fleet and roads. The Chinese fleet has a similar composition to that of Europe, and the database was well suited to describe the emissions of traffic on urban infrastructure (Sun, Schmeid et al. 2014). Many measurements of vehicles are required to generate robust emissions factors, since even minor variations in testing procedures can result in different outputs from the same vehicle (Franco, Kousoulidou et al. 2013).

There are a small number of publicly available microscopic emissions models. MOtor Vehicle Emissions Simulator (MOVES) is the US Environmental Protection Agency (EPA) emissions model for mobile sources, designed for use at scales from national to project. The latest version (MOVES2014a) was released in November 2015 and there have been minor revisions since. It deals with on and off-road emissions and includes calculations for emissions of over 100 compounds including those from fuel evaporation, brake and tyre wear. For details see (https://www.epa.gov/moves). Three simpler microscopic emission models (VT-Micro, EMIT and POLY) were ranked against CMEM, using the same input data from light-duty vehicles from four vehicle classes in two Chinese cities. Different models were found to have strengths in particular aspects, such as speed or better accuracy for certain pollutants (Ma, Lei et al. 2012). Some microscopic emissions models, such as CMEM deal with detail such as hot and cold running, but currently model only a few pollutants: $\mathrm{NO}_{\mathrm{x}}$, total hydrocarbons, $\mathrm{CO}_{2}, \mathrm{CO}$ and do not consider emissions due to evaporation or brake and tyre wear. COPERT Street Level is a 
more detailed version of the European emissions inventory software, COPERT (COmputer Programme to calculate Emissions from Road Transport, http://emisia.com/products/copert). It has similar resolution to MOVES and calculates the pollutants $\mathrm{CO}, \mathrm{CO}_{2}, \mathrm{NO}_{\mathrm{x}}, \mathrm{PM}$ and VOC. PARAMICS (PARAllel MICroscopic traffic Simulator, http://www.paramics-online.com) Monitor is an add-on for the PARAMICS traffic simulator, it models $\mathrm{CO}, \mathrm{CO}_{2}$, total $\mathrm{HC}, \mathrm{NO}_{\mathrm{x}}$, PM and fuel consumption. There is also an add-on that couples the model to CMEM. The AIMSUN (Advanced Interactive Microscopic Simulator for Urban and Non-Urban networks, https://www.aimsun.com) emissions model is easy to calibrate and implement, but the calibration may not apply well to conditions that differ from those of the calibration (Bover, Zhu et al. 2013). The TRANSIMS (TRansportation ANalysis and SIMulation System, https://transims-studio.soft112.com) system of models contains an emissions simulator.

A preliminary study of an artificial neural network (ANN) approach to fuel and emissions modelling used 26 vehicles. (Dia and Boongrapue 2015). Results for fuel consumption had 96\% to $98 \%$ accuracy; emissions data $70 \%$ to $97 \%$ accuracy; depending upon the pollutant modelled and the vehicle. To realise the potential of ANN in emissions modelling, it needs to be integrated with microscopic traffic models.

The accuracy of all models is limited by the quality of the emissions factors used in their calculations. The accuracy of predictions of some regulated pollutant measurements is better than others. $\mathrm{CO}, \mathrm{NO}_{\mathrm{x}}$, total VOC, PM mass and $\mathrm{CO}_{2}$ are well understood as a function of driving conditions, due to the large number of measurements. Others have been less well evaluated: $\mathrm{NO}_{2}, \mathrm{NH}_{3}$, individual VOC, $\mathrm{PAH}, \mathrm{PM}$ as a function of size and number, and heavy metals (Fallah Shorshani, André et al. 2015). The quality and quantity of the emissions of pollutants is related to the power output of a vehicle's engine. A common method takes that data from a microscopic traffic simulation and uses it to calculate emissions using 'vehicle specific power' (VSP) (Fontes, Fernandes et al. 2014). For example, P $\Delta \mathrm{P}$ (engine power, and change in 
engine power) software, based on drive cycles from a large database of Australian emissions tests. Validation gave average $\mathrm{R}^{2}$ values of 0.65 for $\mathrm{NO}_{\mathrm{x}}$ and 0.93 for $\mathrm{CO}_{2} /$ fuel consumption (Smit 2013). However, some power-based models may not be sufficiently sensitive to the small changes in engine power that can have significant effects on emissions (Zhu 2015).

Caution is required when selecting emission factors for use in models, particularly data from vehicle manufacturers. That data was suspect, even before the Volkswagen scandal (Boretti 2017). Engineers at an independent European tester found that manufacturers' tests underestimated exhaust emissions (Schmidt and Johannsen 2010). Car makers were shown to have manipulated load tests, estimates of vehicles' rolling and wind resistance, to skew emissions tests by independent testers. Testers carried out alterations such as not charging the battery, over-inflating tyres, disabling power steering pumps and taping the edges of windows and other gaps to decrease wind and rolling resistance. When regular production vehicles were used instead, fuel economy was decreased by about $12 \%$. The gap between advertised and actual fuel economy figures were as large as 50\% (Dings 2013, Mock and German 2015). In the so called "Dieselgate" scandal, centred around Volkswagen, it was found that cars powered by diesel engines had been releasing $\mathrm{NO}_{\mathrm{x}}$ at a rate more than 4 times that allowed by European regulations. Modelling gave a median estimate of an additional 1,200 premature deaths, or 13,000 life-years lost and 1.9 billion EUR in associated costs, across Europe caused by the extra emissions over the time these vehicles were being sold (2008-2015) (Guillaume, Robert et al. 2017).

\subsubsection{Real time emissions data}

Real-time data is one of the major benefits promised by Intelligent Transport Systems (ITS) including connected, interacting sensors, controllers and vehicles. A service on the Google Maps platform, called "Emission Map," used a combination of data from traffic loop sensors and 
emission calculations from MOVES to give a visualisation of near real-time traffic emissions in Seattle, USA. It (Ma, Yu et al. 2012).

An ever increasing range of technologies are being used in creative ways to calculate emissions. Radar speed detectors were used to reconstruct vehicle trajectories, which became the input to CMEM, to calculate the resulting emissions and fuel consumption (Chen, Yang et al. 2014). The GPS trajectories of 32,000 taxis over 2 months on a road network in Beijing were used to generate instantaneous information on fuel consumption and emission of vehicles. Where data was sparse, a Bayesian Network model, Traffic Volume Inference (TVI) was used to interpolate (Shang, Zheng et al. 2014). $\mathrm{NO}_{\mathrm{x}}$ was estimated from GPS tracks of vehicle movements via nonlinear optimisation (Chen, Bekhor et al. 2016). A Spanish study collected signals from on-board diagnostic systems in cars via mobile phones. The phones also collected GPS coordinates and the information was combined to give second by second trip and emissions data (Garcia-Castro and Monzon 2014).

In a Belgian study, exposure of cyclists to black carbon was found to correlate with noise measurements (Dekoninck, Botteldooren et al. 2015). Another study measured personal exposure to microfine particles with personal monitoring. The measurements were made on repeated traverses (on different times of day, different days and different seasons) of a route that included well frequented urban microenvironments. It found the highest exposures from walking or biking along highly-trafficked routes and using public buses. Exposure to ultrafine particles was significantly lower in modern cars, with efficient filters and recirculated air (Spinazzè, Cattaneo et al. 2015). Personal exposure monitors are expensive, may be inaccurate or may not record locational information. To overcome these limitations, a study used smart phone tracking combined with estimates of ambient pollution concentrations to estimate personal exposure ( $\mathrm{Su}$, Jerrett et al. 2015). 


\subsection{Dispersion models}

Dispersion modelling is a complex science and the models can be very computationally intensive. For accurate prediction of the fate of the products of combustion, models must calculate not just dispersion, but also the complex chemical and physical transformations that occur over time.

Dispersion of emissions near a source can be modelled by Gaussian models; these are of two main types, plume or puff. Plume models assume steady-state conditions; puff models simulate instantaneous releases in a changing environment and are computationally more demanding. A combination of the two approaches can give good results (Fallah Shorshani, André et al. 2015).

The US EPA have a number of freely available atmospheric dispersion models, developed for a range of purposes. These include AEROMOD (continuously updated), a steady-state plume model that can deal with surface and elevated sources on all types of terrain. CALPUFF is a nonsteady-state puff dispersion model that includes the effects of terrain and meteorology and various transformations of emissions over time. CALINE3, a steady-state Gaussian dispersion model for highway pollution in relatively uncomplicated terrain and has calculations for traffic hot-spots and queuing; it allows for meteorological data input. CAL3QHCR is a carbon monoxide model with queuing at signalised intersections and hot spot calculations; it includes meteorological data as an input. The EPA also produces 15 alternative emission dispersion models of varying complexity. AEROMOD uses CAL3QHCR as a meteorological data preprocessor and AERMAP as a terrain pre-processor. The Operational Street Pollution Model (OSPM, Aarhus University, Denmark) is a street canyon circulation model that accounts for building geometry and wind (Kakosimos, Hertel et al. 2010). Atmospheric Dispersion Modelling System - Roads (ADMS-Roads, Cambridge Environmental Research Consultants, Cambridge, UK) is an advanced dispersion model. R-LINE is a freely available research-grade dispersion model produced by the University of North Carolina and US EPA. MyAir is an EU model evaluation toolkit, it was used to compare the performance of four models in predicting the 
603 dispersion of a tracer gas to a large array of sensors. ADMS-Roads, AEROMOD (volume

604

605 source) and RLINE performed better than CALINE (Stocker, Heist et al. 2013).

Recently, there has been an increasing popularity of computational fluid dynamics (CFD) models such as PHOENICS (Chen, Lu et al. 2017) and FLUIDITY (Aristodemou, Boganegra et al. 2018) over the conventional Gaussian-type dispersion models. A CFD emission model was able to show detail such as eddies generated by cross-streets and increased concentrations of pollutants in the lower leeward sides of street canyons (Mumovic, Crowther et al. 2006). A study examined the dispersion and chemical interactions and of ultrafine particles (UFP) from vehicle exhaust-pipes to the near-road environment. The study used an aerosol dynamics-CFD coupled model. It was found that omitting atmospheric boundary layer conditions (wind profile and turbulence quantities) from activity-based emission models resulted in an overestimate of the dilution of emissions in the wake of vehicles. This led to a five-fold underestimate of the nucleation rate. (Huang, Gong et al. 2014). FLUIDITY is an open source simulator that incorporates an anisotropic adaptive unstructured mesh and large eddy simulations (LES). This approach improves predictions by increasing resolution where required and improving the representation of turbulence. The simulation was used to model the effects of increased building height on the distribution of traffic pollution. It was able to reproduce wind tunnel measurements well, with differences ranging from 3\% to 37\% (Aristodemou, Boganegra et al. 2018)

A microscopic dispersion model used the "Random Forest" ensemble learning method for predicting roadside concentrations of $\mathrm{CO}$ and $\mathrm{NO}_{\mathrm{x}}$ on four urban roads with 5 minutely resolution. This approach gave better results than an artificial neural network, which could not determine the relationship between the traffic and roadside air quality (Song, Wu et al. 2014).

In an Indian study, the US EPA's Industrial Source Complex Short Term model (ISCST3) was used to attribute airborne $\mathrm{PM}_{10}$ pollution in Kanpur City to different sources, including 
transport. GIS was used to break up the study area into $2 \mathrm{~km} \times 2 \mathrm{~km}$ grids. Resolution could be adjusted to any time and space (Behera, Sharma et al. 2011).

\subsection{Summary \& recommendations}

There are a number of microscopic models that will perform well, as long as the required input data is available. Table 3 lists shows combinations of models used in studies to estimate emissions and to evaluate methods to reduce exposure. For simulating traffic, SUMO is an opensource model with excellent capabilities; it can represent car-following, lane-changing and signalised intersections. Commercial models, such as AIMSUN, VISSIM and PARAMICS also perform well and tend to have more polished user interfaces. There are fewer choices for emissions simulators; MOVES is very capable, well supported, comprehensive and widely used. Its popularity is in part due to its being required for compliance purposes in the US. There are also commercial emissions models; COPERT Street Level, P $\Delta \mathrm{P}$ and others built for the above commercial traffic simulators. Dispersion models are available for a range of applications from the US EPA website; for example: AEROMOD can be used for scales of up to $50 \mathrm{~km}$. Commercial offerings include OSPM, to model dispersion in street canyons and there are versions of ADMS models for different scales. Promising developments include data-driven approaches to modelling emissions and CFD methods for dispersion.

Table 3. List of recent studies using combinations of microscopic simulations to examine strategies to mitigate pollution

\begin{tabular}{llll}
$\begin{array}{l}\text { topic related to } \\
\text { emissions }\end{array}$ & models used & citation & reduction in pollution \\
\hline \hline $\begin{array}{l}\text { effects of different driving } \\
\text { behaviours }\end{array}$ & VISSIM and CMEM & (Chen and Yu 2007) & 2.6 to 16.5\%
\end{tabular}




\begin{tabular}{|c|c|c|c|}
\hline $\begin{array}{l}\text { strategies for high-occupancy } \\
\text { vehicle (HOV) lanes }\end{array}$ & PARAMICS and CMEM & $\begin{array}{l}\text { (Boriboonsomsin and } \\
\text { Barth 2008) }\end{array}$ & 3 to $17 \%$ \\
\hline $\begin{array}{l}\text { strategies for high-occupancy } \\
\text { vehicle (HOV) lanes }\end{array}$ & VISSIM and VSP & $\begin{array}{l}\text { (Fontes, Fernandes et } \\
\text { al. 2014) }\end{array}$ & 37 to $43 \%$ \\
\hline $\begin{array}{l}\text { Transit Signal Priority (TSP) } \\
\text { system that prioritised buses }\end{array}$ & $\begin{array}{l}\text { PARAMICS and } \\
\text { PARAMICS Monitor } \\
\text { (emissions application) }\end{array}$ & $\begin{array}{l}\text { (Wijayaratna, Dixit et al. } \\
\text { 2013) }\end{array}$ & $-11 \%$ \\
\hline $\begin{array}{l}\text { optimise signal timing on a } \\
\text { large intersection }\end{array}$ & $\begin{array}{l}\text { VISSIM / SUMO and } \\
\text { CMEM }\end{array}$ & (Ma, Jin et al. 2014) & 2.5 to $6.3 \%$ \\
\hline optimisation of signal timing & VISSIM and CMEM & $\begin{array}{l}\text { (Stevanovic, Stevanovic } \\
\text { et al. 2015). }\end{array}$ & $\begin{array}{l}4.5 \% \\
\text { (fuel consumed) }\end{array}$ \\
\hline active speed management & $\begin{array}{l}\text { DRACULA* and non- } \\
\text { linear multiple regression }\end{array}$ & $\begin{array}{l}\text { (Int Panis, Broekx et al. } \\
\text { 2006). }\end{array}$ & -1.1 to $1.2 \%$ \\
\hline active speed management & SUMO and CMEM & $\begin{array}{l}\text { (Grumert, Ma et al. } \\
2015 \text { ) }\end{array}$ & 3.8 to $8.0 \%$ \\
\hline $\begin{array}{l}\text { use of ITS: variable message } \\
\text { signs, highway advisory radio }\end{array}$ & VISSIM, POLARIS & $\begin{array}{l}\text { (Auld, Karbowski et al. } \\
\text { 2016) }\end{array}$ & $\begin{array}{l}2.5 \% \\
\text { (fuel consumed) }\end{array}$ \\
\hline $\begin{array}{l}\text { different designs of } \\
\text { intersections }\end{array}$ & $\begin{array}{l}\text { MOVES and } \\
\text { AEROMOD }\end{array}$ & (Qiu and Li 2015) & $81.7 \%$ \\
\hline $\begin{array}{l}\text { traffic pollution and } \\
\text { dispersion }\end{array}$ & $\begin{array}{l}\text { PARAMICS, CMEM and } \\
\text { AERMET }\end{array}$ & $\begin{array}{l}\text { (Amirjamshidi, Mostafa } \\
\text { et al. 2013) }\end{array}$ & 1 to $12 \%$ \\
\hline license plate restrictions & VISSUM and MOVES & (Pu, Yang et al. 2015) & $6.9 \%$ \\
\hline $\begin{array}{l}\text { different lane configurations, } \\
\text { traffic management strategies }\end{array}$ & $\begin{array}{l}\text { TransModeler and } \\
\text { MOVES }\end{array}$ & (Xiong, Zhu et al. 2015) & 0.22 to $0.72 \%$ \\
\hline $\begin{array}{l}\text { mitigation of harm to } \\
\text { vulnerable populations }\end{array}$ & $\begin{array}{l}\text { MOVES and RLINE } \\
\text { (10 m spatial resolution) }\end{array}$ & $\begin{array}{l}\text { (Batterman, Ganguly et } \\
\text { al. 2015) }\end{array}$ & measures not quantified \\
\hline
\end{tabular}

$650 *$ Dynamic Route Assignment Combining User Learning and microsimulAtion, Institute for Transport 651 Studies, University of Leeds, UK

\section{Conclusions}

The airborne emissions from traffic present significant, well established hazards to many of the people in cities. The current state of the science is able to model traffic emissions with very fine resolution. With the use of microsimulations, temporal resolution is typically one second and spatial resolution tens of metres. This detail is necessary because the chemistry of emissions changes rapidly over time and space. The most polluting phases of driving happen over short intervals, such as after starts and with the acceleration and deceleration of congested traffic. There are a number of software packages available for the various aspects of emissions modelling, both commercial and open source. New research is applying novel approaches, such as agent-based models, neural networks and ensemble learning to increase speed, detail and 
scope. Models are used for evaluating mitigation measures, either managing the traffic to improve flow and minimise emissions, or separating people from the traffic with under or overpasses. The rate of data being produced from multiple types of road sensors is ever increasing. Vehicles are also tracked using wireless radio signals from mobile phones and other transmitting devices. Many cities integrate these multiple data streams in intelligent transport systems, reducing emissions by improving the effectiveness of road and transport networks. Information from ITS has also enabled the deployment of detailed real time traffic emissions models, offering the possibility for people to plan travel or close windows to avoid potentially harmful exposure. Spatially detailed simulations can be combined with demographic data to provide targeted information and risk analyses. Traffic emissions models have grown beyond only being tools for the planning of infrastructure, to versatile instruments that can inform many disciplines and help to improve the health of city-dwellers.

\section{Acknowledgemens}

This review was funded by the Clean Air and Urban Landscapes (CAUL) hub of the Australian National Environmental Science Programme (NESP). We would also like to acknowledge the thoughtful reviews by the anonymous reviewers whose input significantly improved this paper.

\section{References}

Abbott-Jard, M., H. Shah and A. Bhaskar (2013). Empirical evaluation of Bluetooth and Wifi scanning for road transport. 36th Australasian Transport Research Forum, ATRF 2013, Australasian Transport Research Forum. Abedi, N., A. Bhaskar and E. Chung (2013). Bluetooth and Wi-Fi MAC address based crowd data collection and monitoring: Benefits, challenges and enhancement. 36th Australasian Transport Research Forum, ATRF 2013, Australasian Transport Research Forum.

Alghamdi, A., T. Nadeem and M. Cetin (2014). BlueEye: A bluetooth-based vehicle location identification system for queue length estimation at signalized intersections. 21st World Congress on Intelligent 
692 Transport Systems: Reinventing Transportation in Our Connected World, ITSWC 2014, Intelligent

693 Transport Systems (ITS).

694 Aliari, Y. and A. Haghani (2012). Bluetooth sensor data and ground truth testing of reported travel times.

695 Transportation Research Record: 167-172.

696 Amirjamshidi, G., T. S. Mostafa, A. Misra and M. J. Roorda (2013). "Integrated model for microsimulating vehicle emissions, pollutant dispersion and population exposure." Transportation Research Part D: Transport and Environment 18(1): 16-24.

699 Antoniou, C., C. Lima Azevedo, L. Lu, F. Pereira and M. Ben-Akiva (2015). "W-SPSA in practice:

700 Approximation of weight matrices and calibration of traffic simulation models." Transportation Research

$701 \quad$ Part C: Emerging Technologies.

702 Apte, J. S., K. P. Messier, S. Gani, M. Brauer, T. W. Kirchstetter, M. M. Lunden, J. D. Marshall, C. J. Portier, R. C. H. Vermeulen and S. P. Hamburg (2017). "High-Resolution Air Pollution Mapping with Google Street View Cars: Exploiting Big Data." Environmental Science \& Technology 51(12): 6999-7008. Aristodemou, E., L. M. Boganegra, L. Mottet, D. Pavlidis, A. Constantinou, C. Pain, A. Robins and H. ApSimon (2018). "How tall buildings affect turbulent air flows and dispersion of pollution within a neighbourhood." Environmental Pollution 233: 782-796.

Auld, J., D. Karbowski, V. Sokolov and N. Kim (2016). A Disaggregate Model System for Assessing the Energy Impact of Transportation at the Regional Level. 95th Annual Meeting of the Transportation Research Board. Washington DC.

Aust, N., P. Watkiss, P. Boulter and K. Bawden (2013). Methodology for Valuing the health impacts of changes in particle emissions- final report, NSW Environment Protection Authority.

Austroads (2006). The use and application of microsimulation traffic models. Sydney, Australia: 103. Bachmann, C., B. Abdulhai, M. J. Roorda and B. Moshiri (2013). "A comparative assessment of multisensor data fusion techniques for freeway traffic speed estimation using microsimulation modeling." Transportation Research Part C: Emerging Technologies 26: 33-48.

Bachmann, C., M. J. Roorda, B. Abdulhai and B. Moshiri (2013). "Fusing a bluetooth traffic monitoring system with loop detector data for improved freeway traffic speed estimation." Journal of Intelligent Transportation Systems: Technology, Planning, and Operations 17(2): 152-164.

Badyda, A. J., P. Dabrowiecki, P. O. Czechowski and G. Majewski (2015). "Risk of bronchi obstruction among non-smokers-review of environmental factors affecting bronchoconstriction." Respiratory Physiology and Neurobiology 209: 39-46.

Balaji Yelchuru, B., V. Adams, E. Hurley and V. Bonifera (2011). AERIS: State of-the-Practice Scan of Environmental Models. Washington DC, USA, Research and Innovative Technology Administration (RITA): 74.

Barthélemy, J. and T. Carletti (2017). An adaptive agent-based approach to traffic simulation. Transportation Research Procedia.

Batterman, S., R. Ganguly and P. Harbin (2015). "High resolution spatial and temporal mapping of traffic-related air pollutants." International Journal of Environmental Research and Public Health 12(4): 3646-3666.

Beelen, R., G. Hoek, P. A. van den Brandt, R. A. Goldbohm, P. Fischer, L. J. Schouten, M. Jerrett, E. Hughes, B. Armstrong and B. Brunekreef (2008). "Long-term effects of traffic-related air pollution on mortality in a Dutch cohort (NLCS-AIR study)." Environmental Health Perspectives 116(2): 196-202. Behera, S. N., M. Sharma, O. Dikshit and S. P. Shukla (2011). "GIS-based emission inventory, dispersion modeling, and assessment for source contributions of particulate matter in an urban environment."

Water, Air, and Soil Pollution 218(1-4): 423-436.

Boretti, A. (2017). "The Future of the Internal Combustion Engine after "diesel-Gate"." 2017-July(July). Boriboonsomsin, K. and M. Barth (2008). "Impacts of freeway high-occupancy vehicle lane configuration on vehicle emissions." Transportation Research Part D: Transport and Environment 13(2): 112-125. Bover, P., S. Zhu and L. Ferreira (2013). "Modelling vehicle emissions for Australian conditions." $\underline{\text { Road }}$ and Transport Research 22(4): 15-29.

BTRE (2005). Health impacts of transport emissions in Australia: economic costs. B. o. T. a. R. Economics, Department of Transport and Regional Services.

Cao, X., W. Young and M. Sarvi (2013). Exploring duration of lane change execution. 36th Australasian Transport Research Forum, ATRF 2013, Australasian Transport Research Forum. Castiglione, J., M. Bradley and J. Gliebe (2015). Activity-based travel demand models: a primer. The second strategic highway research program. Washington D.C., Transportation Research Board. 
Chan, Y. C., R. W. Simpson, G. H. McTainsh, P. D. Vowles, D. D. Cohen and G. M. Bailey (1999).

"Source apportionment of PM2.5 and PM10 in Brisbane (Australia) by receptor modelling." Atmospheric Environment 33(19): 3251-3268.

Chen, K. and L. Yu (2007). "Microscopic Traffic-Emission Simulation and Case Study for Evaluation of Traffic Control Strategies." Journal of Transportation Systems Engineering and Information Technology 7(1): 93-99.

Chen, S., S. Bekhor, Yuval and D. M. Broday (2016). "Aggregated GPS tracking of vehicles and its use as a proxy of traffic-related air pollution emissions." Atmospheric Environment 142: 351-359.

Chen, S. L., J. Lu and W. W. Yu (2017). "A quantitative method to detect the ventilation paths in a mountainous urban city for urban planning: A case study in guizhou, China." Indoor and Built Environment 26(3): 422-437.

Chen, Z., M. T. Salam, S. P. Eckel, C. V. Breton and F. D. Gilliland (2015). "Chronic effects of air pollution on respiratory health in Southern California children: Findings from the Southern California Children's Health Study." Journal of Thoracic Disease 7(1): 46-58.

Chen, Z., C. Yang and A. Chen (2014). "Estimating fuel consumption and emissions based on reconstructed vehicle trajectories." Journal of Advanced Transportation 48(6): 627-641.

Chong-White, C., G. Millar, F. Johnson and S. Shaw (2014). The SCATS and the environment study: Introduction and preliminary results. 34th Australasian Transport Research Forum, ATRF 2011, Australasian Transport Research Forum.

Chong-White, C., G. Millar and S. Shaw (2013). SCATS and the environment study: An indication of road customer value. 36th Australasian Transport Research Forum, ATRF 2013, Australasian Transport Research Forum.

Coker, E., J. Ghosh, M. Jerrett, V. Gomez-Rubio, B. Beckerman, M. Cockburn, S. Liverani, J. Su, A. Li, M. L. Kile, B. Ritz and J. Molitor (2015). "Modeling spatial effects of $\mathrm{PM}<$ inf $>2.5</$ inf $>$ on term low birth weight in Los Angeles County." Environmental Research 142: 354-364.

Daniels, M. J., F. Dominici, J. M. Samet and S. L. Zeger (2000). "Estimating particulate matter-mortality dose-response curves and threshold levels: An analysis of daily time-series for the 20 largest US cities." American Journal of Epidemiology 152(5): 397-406.

DAPPLE. (2009). "Dispersion of Air Pollution and its Penetration into the Local Environment." from http://www.dapple.org.uk.

Dekoninck, L., D. Botteldooren and L. Int Panis (2015). "Using city-wide mobile noise assessments to estimate bicycle trip annual exposure to Black Carbon." Environment International 83: 192-201. Dia, H. and N. Boongrapue (2015). "Vehicle emission models using Australian fleet data." Road and Transport Research 24(1): 14-26.

Dings, J. (2013) "Mind the Gap! Why official car fuel economy figures don't match up to reality." El-Fadel, M. (2002). "Grade separations for traffic congestion relief: Air quality and noise implications." International Journal of Environmental Studies 59(6): 689-705.

Elangasinghe, M. A., K. N. Dirks, N. Singhal, S. B. Costello, I. Longley and J. A. Salmond (2014). "A simple semi-empirical technique for apportioning the impact of roadways on air quality in an urban neighbourhood." Atmospheric Environment 83: 99-108.

ERMES. (2015). "Leading EU Models." 2015, from http://www.ermesgroup.eu/web/leading_EU_models.

European Environment Agency (2007). EMEP/EEA air pollutant emission inventory guidebook, Technical guidance to prepare national emission inventories. EEA Technical reports. Office for Official Publications of the European Communities, Luxembourg.

Fallah Shorshani, M., M. André, C. Bonhomme and C. Seigneur (2015). "Modelling chain for the effect of road traffic on air and water quality: Techniques, current status and future prospects." Environmental Modelling and Software 64: 102-123.

Feng, X., Y. Ge, C. Ma, J. Tan, L. Yu, J. Li and X. Wang (2014). "Experimental study on the nitrogen dioxide and particulate matter emissions from diesel engine retrofitted with particulate oxidation catalyst." Science of the Total Environment 472: 56-62.

Fontes, T., P. Fernandes, H. Rodrigues, J. M. Bandeira, S. R. Pereira, A. J. Khattak and M. C. Coelho (2014). "Are HOV/eco-lanes a sustainable option to reducing emissions in a medium-sized European city?" Transportation Research Part A: Policy and Practice 63: 93-106. 
802 Fontes, T., S. R. Pereira, P. Fernandes, J. M. Bandeira and M. C. Coelho (2015). "How to combine 803 different microsimulation tools to assess the environmental impacts of road traffic? Lessons and Forehead, H. I., C. Murphy, P. Perez and I. Wadlow (2017). Quiet Streets, Clean Air. International Symposium on Next Generation Infrastructure. London, UK.

Franco, V., M. Kousoulidou, M. Muntean, L. Ntziachristos, S. Hausberger and P. Dilara (2013). "Road vehicle emission factors development: A review." Atmospheric Environment 70: 84-97.

Gao, H. O. and L. S. Johnson (2009). "Methods of analysis for vehicle soak time data." Transportation Research Part A: Policy and Practice 43(8): 744-754.

Garcia-Castro, A. and A. Monzon (2014). "Using floating car data to analyse the effects of ITS measures and Eco-driving." Sensors (Switzerland) 14(11): 21358-21374.

Gehring, U., R. Beelen, M. Eeftens, G. Hoek, K. De Hoogh, J. C. De Jongste, M. Keuken, G. H. Koppelman, K. Meliefste, M. Oldenwening, D. S. Postma, L. Van Rossem, M. Wang, H. A. Smit and B. Brunekreef (2015). "Particulate matter composition and respiratory health the PIAMA birth cohort study." Epidemiology 26(3): 300-309.

Gois, V., H. Maciel, L. Nogueira, C. Almeida, P. Torres, S. Mesquita and F. Ferreira (2007). A detailed urban road traffic emissions inventory model using aerial photography and GPS surveys EPA's 16th Annual International Emission Inventory Conference. Raleigh, NC.

Gordon, T. D., A. A. Presto, A. A. May, N. T. Nguyen, E. M. Lipsky, N. M. Donahue, A. Gutierrez, M. Zhang, C. Maddox, P. Rieger, S. Chattopadhyay, H. Maldonado, M. M. Maricq and A. L. Robinson (2014). "Secondary organic aerosol formation exceeds primary particulate matter emissions for light-duty gasoline vehicles." Atmospheric Chemistry and Physics 14(9): 4661-4678.

Grumert, E., X. Ma and A. Tapani (2015). "Analysis of a cooperative variable speed limit system using microscopic traffic simulation." Transportation Research Part C: Emerging Technologies 52: 173-186. Guillaume, P. C., M. Robert, A. Akshay, C. D. Irene, D. E. Sebastian, L. S. Raymond and R. H. B. Steven (2017). "Public health impacts of excess NO x emissions from Volkswagen diesel passenger vehicles in Germany." Environmental Research Letters 12(3): 034014.

Hansen, Å. M., H. Wallin, M. L. Binderup, M. Dybdahl, H. Autrup, S. Loft and L. E. Knudsen (2004). "Urinary 1-hydroxypyrene and mutagenicity in bus drivers and mail carriers exposed to urban air pollution in Denmark." Mutation Research - Genetic Toxicology and Environmental Mutagenesis 557(1): 7-17.

Harrison, R. M. and D. C. Beddows (2017). "Efficacy of Recent Emissions Controls on Road Vehicles in Europe and Implications for Public Health." Scientific Reports 7(1).

HBEFA. (2015). "Handbook of Emission Factors for Road Transport (HBEFA)." from http://www.hbefa.net/e/index.html.

He, C., J. Li, Z. Ma, J. Tan and L. Zhao (2015). "High NO2/NOx emissions downstream of the catalytic diesel particulate filter: An influencing factor study." Journal of Environmental Sciences (China) 35: 5561.

Holguin, F. and M. C. McCormack (2014). "Right from wrong: The effect of traffic-related pollution on the right heart." American Journal of Respiratory and Critical Care Medicine 189(9): 1018-1019. Houghton, N., J. McRobert, S. Patrick and D. Tsolakis (2003). Planning for freight in urban areas, Austroads: 79 .

Hu, Y., Z. Bai, L. Zhang, X. Wang, L. Zhang, Q. Yu and T. Zhu (2007). "Health risk assessment for traffic policemen exposed to polycyclic aromatic hydrocarbons (PAHs) in Tianjin, China." Science of the Total Environment 382(2-3): 240-250.

Huang, L., S. L. Gong, M. Gordon, J. Liggio, R. Staebler, C. A. Stroud, G. Lu, C. Mihele, J. R. Brook and C. Q. Jia (2014). "Aerosol-computational fluid dynamics modeling of ultrafine and black carbon particle emission, dilution, and growth near roadways." Atmospheric Chemistry and Physics 14(23): 12631-12648. Huynh, N., M. R. Namazi-Rad, P. Perez, M. J. Berryman, Q. Chen and J. Barthelemy (2013). Generating a synthetic population in support of agent-based modeling of transportation in Sydney. 20th International Congress on Modelling and Simulation. Adelaide, Australia.

INRIX. (2018). "INRIX Traffic." Retrieved 15/5/2017, from http://inrix.com/products/traffic/. Int Panis, L., S. Broekx and R. Liu (2006). "Modelling instantaneous traffic emission and the influence of traffic speed limits." Science of the Total Environment 371(1-3): 270-285. Jánošíkova, L., J. Slavík and M. Koháni (2014). "Estimation of a route choice model for urban public transport using smart card data." Transportation Planning and Technology 37(7): 638-648. 
Jha, M., G. Gopalan, A. Garms, B. P. Mahanti, T. Toledo and M. E. Ben-Akiva (2004). Development and calibration of a large-scale microscopic traffic simulation model. Transportation Research Record: 121 131.

Juster, R. M., S. E. Young and E. Sharifi (2014). Measuring performance on interrupted flow facilities with GPS probe and bluetoothtm traffic monitoring data. 21st World Congress on Intelligent Transport Systems: Reinventing Transportation in Our Connected World, ITSWC 2014, Intelligent Transport Systems (ITS).

Kakosimos, K. E., O. Hertel, M. Ketzel and R. Berkowicz (2010). "Operational Street Pollution Model (OSPM) - A review of performed application and validation studies, and future prospects." Environmental Chemistry 7(6): 485-503.

Kaushik, K., E. Sharifi, S. E. Young and B. Baghaei (2014). Comparison of national performance measure data set (NPMRDS) with bluetooth traffic monitoring (BTM) data and I-95 corridor coalition Vehicle Probe Project (VPP) data. 21st World Congress on Intelligent Transport Systems: Reinventing Transportation in Our Connected World, ITSWC 2014, Intelligent Transport Systems (ITS). Kheirbek, I., S. Johnson, Z. Ross, G. Pezeshki, K. Ito, H. Eisl and T. Matte (2012). "Spatial variability in levels of benzene, formaldehyde, and total benzene, toluene, ethylbenzene and xylenes in New York City: A land-use regression study." Environmental Health: A Global Access Science Source 11(1).

Khoei, A. M., A. Bhaskar and E. Chung (2013). Travel time prediction on signalised urban arterials by applying SARIMA modelling on Bluetooth data. 36th Australasian Transport Research Forum, ATRF 2013, Australasian Transport Research Forum.

Knapen, L., T. Bellemans, M. Usman, D. Janssens and G. Wets (2014). "Within day rescheduling microsimulation combined with macrosimulated traffic." Transportation Research Part C: Emerging Technologies 45: 99-118.

Knibbs, L. D., T. Cole-Hunter and L. Morawska (2011). "A review of commuter exposure to ultrafine particles and its health effects." Atmospheric Environment 45(16): 2611-2622.

Kokkinogenis, Z., L. Sanchez Passos, R. Rossetti and J. Gabriel (2011). "Towards the next-generation traffic simulation tools: A first evaluation." Proc. of DSIE2011 6th Doctoral Symposium in Informatics Engineering.

Kumar, P., M. Ketzel, S. Vardoulakis, L. Pirjola and R. Britter (2011). "Dynamics and dispersion modelling of nanoparticles from road traffic in the urban atmospheric environment-A review." Journal of Aerosol Science 42(9): 580-603.

Kumar, S. V. and L. Vanajakshi (2015). "Short-term traffic flow prediction using seasonal ARIMA model with limited input data." European Transport Research Review 7(3).

Kumar, S. V., L. Vanajakshi and S. C. Subramanian (2011). Location-based data for estimated traffic on urban arterial in heterogeneous traffic conditions. Transportation Research Record: 16-22.

Lighthill, M. J. and G. B. Whitham (1955). "On kinematic waves II: A theory of traffic flow on long crowded roads." Proceedings of the Royal Society 229(1178): 317-345.

Liu, Y., S. Tao, Y. Yang, H. Dou, Y. Yang and R. M. Coveney (2007). "Inhalation exposure of traffic police officers to polycyclic aromatic hydrocarbons (PAHs) during the winter in Beijing, China." $\underline{\text { Science }}$ of The Total Environment 383(1-3): 98-105.

Lu, F., D. Xu, Y. Cheng, S. Dong, C. Guo, X. Jiang and X. Zheng (2015). "Systematic review and metaanalysis of the adverse health effects of ambient PM2.5 and PM10 pollution in the Chinese population." Environmental Research 136: 196-204.

Lv, Y., Y. Duan, W. Kang, Z. Li and F. Y. Wang (2015). "Traffic Flow Prediction with Big Data: A Deep Learning Approach." IEEE Transactions on Intelligent Transportation Systems 16(2): 865-873.

Ma, X., J. Jin and W. Lei (2014). "Multi-criteria analysis of optimal signal plans using microscopic traffic models." Transportation Research Part D: Transport and Environment 32: 1-14.

Ma, X., W. Lei, I. Andréasson and H. Chen (2012). "An Evaluation of Microscopic Emission Models for Traffic Pollution Simulation Using On-board Measurement." Environmental Modeling and Assessment 17(4): 375-387.

Ma, X., R. Yu and Y. Wang (2012). Developing regional map-based platform for spatial and temporal assessment of traffic emission inventory. 12th COTA International Conference of Transportation Professionals: Multimodal Transportation Systems - Convenient, Safe, Cost-Effective, Efficient, CICTP 2012, Beijing.

Maddock, J. (2015). Traffic Data Manager, Main Roads Western Australia. 
Mao, L., Y. Qiu, C. Kusano and X. Xu (2012). "Predicting regional space-time variation of PM2.5 with land-use regression model and MODIS data." Environmental Science and Pollution Research 19(1): 128138.

Marquez, L. and V. Salim (2007). "Assessing impacts of urban freight measures on air toxic emissions in Inner Sydney." Environmental Modelling and Software 22(4): 515-525.

Mellios, G. and L. Ntziachristos (2012). Gasoline evaporation from vehicles. EMEP/EEA emission inventory guidebook. Luxembourg, European Environment Agency.

Michau, G., A. Nantes and E. Chung (2013). Towards the retrieval of accurate od matrices from bluetooth data: Lessons learned from 2 years of data. 36th Australasian Transport Research Forum, ATRF 2013, Australasian Transport Research Forum.

Mock, P. and J. German (2015). The future of vehicle emissions testing and compliance, The International Council on Clean Transportation.

Mumovic, D., J. M. Crowther and Z. Stevanovic (2006). "Integrated air quality modelling for a designated air quality management area in Glasgow." Building and Environment 41(12): 1703-1712.

Nagel, K., B. Kickhöfer and J. W. Joubert (2014). Heterogeneous tolls and values of time in multi-agent transport simulation. 5th International Conference on Ambient Systems, Networks and Technologies, ANT 2014 and 4th International Conference on Sustainable Energy Information Technology, SEIT 2014, Hasselt, Elsevier.

Nantes, A., D. Ngoduy, A. Bhaskar, M. Miska and E. Chung (2015). "Real-time traffic state estimation in urban corridors from heterogeneous data." Transportation Research Part C: Emerging Technologies. National Research Council Committee on Health Impact, A. (2011). The National Academies Collection: Reports funded by National Institutes of Health. Improving Health in the United States: The Role of Health Impact Assessment. Washington (DC), National Academies Press (US)

National Academy of Sciences.

NYCCAS. (2018). "New York City Community Air Survey." from http://www1.nyc.gov/site/doh/data/data-publications/air-quality-nyc-community-air-survey.page. Olvera, H. A., O. Jimenez and E. Provencio-Vasquez (2014). "Modeling particle number concentrations along Interstate 10 in El Paso, Texas." Atmospheric Environment 98: 581-590.

Penttinen, M., F. Diederichs, K. Pagle, E. Portouli and P. Rämä (2014). Impact evaluation methodology for collaborative transport applications. 21st World Congress on Intelligent Transport Systems: Reinventing Transportation in Our Connected World, ITSWC 2014, Intelligent Transport Systems (ITS). Pu, Y., C. Yang, H. Liu, Z. Chen and A. Chen (2015). "Impact of license plate restriction policy on emission reduction in Hangzhou using a bottom-up approach." Transportation Research Part D: Transport and Environment 34: 281-292.

Qiu, Z. and X. Li (2015). "At-grade intersection configuration influences on pedestrian exposure to PM2.5." Clean Technologies and Environmental Policy.

Qu, L., M. Li, D. Chen, K. Lu, T. Jin and X. Xu (2015). "Multivariate analysis between driving condition and vehicle emission for light duty gasoline vehicles during rush hours." Atmospheric Environment 110: 103-110.

Requia, W. J., C. D. Higgins, M. D. Adams, M. Mohamed and P. Koutrakis (2018). "The health impacts of weekday traffic: A health risk assessment of PM2.5 emissions during congested periods." Environment International 111: 164-176.

Rice, M. B., P. L. Ljungman, E. H. Wilker, K. S. Dorans, D. R. Gold, J. Schwartz, P. Koutrakis, G. R. Washko, G. T. O'Connor and M. A. Mittleman (2015). "Long-term exposure to traffic emissions and fine particulate matter and lung function decline in the Framingham Heart Study." American Journal of Respiratory and Critical Care Medicine 191(6): 656-664.

Rückerl, R., A. Schneider, S. Breitner, J. Cyrys and A. Peters (2011). "Health effects of particulate air pollution: A review of epidemiological evidence." Inhalation Toxicology 23(10): 555-592.

Ryu, Y. H., J. J. Baik, K. H. Kwak, S. Kim and N. Moon (2013). "Impacts of urban land-surface forcing on ozone air quality in the Seoul metropolitan area." Atmospheric Chemistry and Physics 13(4): 2177 2194.

Salameh, D., A. Detournay, J. Pey, N. Pérez, F. Liguori, D. Saraga, M. C. Bove, P. Brotto, F. Cassola, D. Massabò, A. Latella, S. Pillon, G. Formenton, S. Patti, A. Armengaud, D. Piga, J. L. Jaffrezo, J. Bartzis, E. Tolis, P. Prati, X. Querol, H. Wortham and N. Marchand (2015). "PM2.5 chemical composition in five European Mediterranean cities: A 1-year study." Atmospheric Research 155: 102-117. 
968 Samoli, E., A. Analitis, G. Touloumi, J. Schwartz, H. R. Anderson, J. Sunyer, L. Bisanti, D. Zmirou, J. M.

969 Vonk, J. Pekkanen, P. Goodman, A. Paldy, C. Schindler and K. Katsouyanni (2005). "Estimating the exposure-response relationships between particulate matter and mortality within the APHEA multicity project." Environmental Health Perspectives 113(1): 88-95.

Schmidt, H. and R. Johannsen (2010). Future Development of the EU Directive for Measuring the CO2 Emissions of Passenger Cars - Investigation of the Influence of Different Parameters and the Improvement of Measurement Accuracy, Federal Environment Agency, Germany.

Schrank, D., B. Eisele, T. Lomax and J. Bak (2015). 2015 Urban mobility scorecard, Texas Transportation Institute, The Texas A\&M University System, INRIX Inc: 81.

Shang, J., Y. Zheng, W. Tong, E. Chang and Y. Yu (2014). Inferring gas consumption and pollution emission of vehicles throughout a city. 20th ACM SIGKDD International Conference on Knowledge Discovery and Data Mining, KDD 2014, New York, NY, Association for Computing Machinery. Shen, L. and P. R. Stopher (2013). Should we change the rules for trip identification for GPS travel records? 36th Australasian Transport Research Forum, ATRF 2013, Australasian Transport Research Forum.

Sider, T., G. Goulet-Langlois, N. Eluru and M. Hatzopoulou (2015). "Quantifying the effects of input aggregation and model randomness on regional transportation emission inventories." Transportation. Smit, R. (2006). An examination of congestion in road traffic emsision models and their application to urban road networks. $\mathrm{PhD}$, Griffith University.

Smit, R. (2013). "Development and performance of a new vehicle emissions and fuel consumption software (P $\Delta \mathrm{P})$ with a high resolution in time and space." Atmospheric Pollution Research 4(3): 336-345. Smit, R. (2014). Australian Motor Vehicle Emission Inventory for the National Pollutant Inventory (NPI). St Lucia, Australia, UniQuest Pty Ltd: 45.

Smith, M. C., A. W. Sadek and S. Huang (2008). "Large-Scale microscopic simulation: Toward an increased resolution of transportation models." Journal of Transportation Engineering 134(7): 273-281. Smith, W. B., A. M. Hainen, S. M. Remias, R. S. Freije and D. M. Bullock (2014). Assessing network changes attributed to opening a new 67 mile segment of I-69 using field data from bluetooth probe vehicles. 21st World Congress on Intelligent Transport Systems: Reinventing Transportation in Our Connected World, ITSWC 2014, Intelligent Transport Systems (ITS).

Song, B., J. Wu, Y. Zhou and K. Hu (2014). "Fine-scale prediction of roadside CO and NOx concentration based on a random forest model." Journal of Residuals Science and Technology 11(3): 8389 .

Southern, M. (2015). Traffic Mananagement Centre Supervisor at Department of Planning, Transport and Infrastructure (DPTI).

Spinazzè, A., A. Cattaneo, D. R. Scocca, M. Bonzini and D. M. Cavallo (2015). "Multi-metric measurement of personal exposure to ultrafine particles in selected urban microenvironments." Atmospheric Environment 110: 8-17.

Steerenberg, P. A., S. Nierkens, P. H. Fischer, H. Van Loveren, A. Opperhuizen, J. G. Vos and J. G. C. Van Amsterdam (2001). "Traffic-related air pollution affects peak expiratory flow, exhaled nitric oxide, and inflammatory nasal markers." Archives of Environmental Health 56(2): 167-174.

Stevanovic, A., J. Stevanovic, J. So and M. Ostojic (2015). "Multi-criteria optimization of traffic signals: Mobility, safety, and environment." Transportation Research Part C: Emerging Technologies 55: 46-68. Stocker, J., D. Heist, C. Hood, V. Isakov, D. Carruthers, S. Perry, M. Snyder, A. Venkatram and S. Arunachalam (2013). H15-78: Road source model intercomparison study using new and existing datasets. 15th International Conference on Harmonisation within Atmospheric Dispersion Modelling for Regulatory Purposes, HARMO 2013, Environmental Software and Modelling Group. Stopher, P. R., S. P. Greaves and L. Shen (2013). Comparing two processing routines for GPS traces Lessons learnt. 36th Australasian Transport Research Forum, ATRF 2013, Australasian Transport Research Forum.

Su, J. G., M. Jerrett, Y.-Y. Meng, M. Pickett and B. Ritz (2015). "Integrating smart-phone based momentary location tracking with fixed site air quality monitoring for personal exposure assessment." Science of The Total Environment 506-507: 518-526.

Sun, S., M. Schmeid, D. Bongardt, P. Wüthrich and U. Eichhorst (2014). Modelling energy consumption and GHG emissions of road transport in China: technical paper on GIZ CRTEM/HBEFA-China model, Federal Ministry for the Environment, Nature Conservation, Building and Nuclear Safety, Federal Republic of Germany: 37. 
1024 Sun, Z., P. Hao, X. Ban and D. Yang (2015). "Trajectory-based vehicle energy/emissions estimation for 1025 signalized arterials using mobile sensing data." Transportation Research Part D: Transport and 1026 Environment 34: 27-40.

1027 Szwed, P. and K. Pekala (2014). Map-Matching in a Real-Time Traffic Monitoring Service.

1028 Communications in Computer and Information Science, Springer Verlag. 424: 425-434.

1029 Tang, T., J. Zhang, D. Cao, S. Shuai and Y. Zhao (2014). "Experimental study on filtration and 1030 continuous regeneration of a particulate filter system for heavy-duty diesel engines." Journal of 1031 Environmental Sciences (China) 26(12): 2434-2439.

1032 UN-Habitat (2013). Planning and design for sustainable urban mobility. Global report on human 1033 settelments 2013, United Nations Human Settlements Programme.

1034 Valavanidis, A., K. Fiotakis and T. Vlachogianni (2008). "Airborne particulate matter and human health:

1035 Toxicological assessment and importance of size and composition of particles for oxidative damage and

1036 carcinogenic mechanisms." Journal of Environmental Science and Health - Part C Environmental

1037 Carcinogenesis and Ecotoxicology Reviews 26(4): 339-362.

1038 Vasantha Kumar, S. and L. Vanajakshi (2014). "Urban Arterial Travel Time Estimation Using Buses as

1039 Probes." Arabian Journal for Science and Engineering 39(11): 7555-7567.

1040 Vlahogianni, E. I. (2015). "Optimization of traffic forecasting: Intelligent surrogate modeling."

1041 Transportation Research Part C: Emerging Technologies 55: 14-23.

1042 WHO (2013). Review of evidence on health aspects of air pollution - REVIHAAP project: final technical 1043 report.

1044 Wichmann, H. E. (2007). "Diesel exhaust particles." Inhalation Toxicology 19(SUPPL. 1): 241-244.

1045 Wijayaratna, K., V. Dixit, T. Mao and S. T. Waller (2013). Emissions impacts of transit signal

1046 prioritisation. 36th Australasian Transport Research Forum, ATRF 2013, Australasian Transport

1047 Research Forum.

1048 Wu, Z. and L. R. Rilett (2014). Predicting corridor travel time reliability in real time using bluetooth data.

104921 st World Congress on Intelligent Transport Systems: Reinventing Transportation in Our Connected

1050 World, ITSWC 2014, Intelligent Transport Systems (ITS).

1051 Xia, T., M. Nitschke, Y. Zhang, P. Shah, S. Crabb and A. Hansen (2015). "Traffic-related air pollution and

1052

1053

1054 Xiong, C., Z. Zhu, X. He, X. Chen, S. Zhu, S. Mahapatra, G. L. Chang and L. Zhang (2015). "Developing

1055 a 24-hour large-scale microscopic traffic simulation model for the before-and-after study of a new tolled

1056 freeway in the Washington, DC-Baltimore region." Journal of Transportation Engineering 141(6).

1057 Zhang, H. and H. Cai (2016). Integrating regional travel forecasting model and microscopic traffic model

1058

1059

1060

1061

1062 to assist highway work zone mobility analysis. 2nd International Conference on Geographical Information Systems Theory, Applications and Management, GISTAM 2016, SciTePress. Zhu, S. (2015). Development of vehicle emissions models for Australian conditions. PhD, University of Queensland.

Zhu, S. and L. Ferreira (2013). "Quantifying errors in micro-scale emissions models using a case-study 1063 approach." Transportation Research Part D: Transport and Environment 21: 19-25. 